\title{
Water Retention and Field Soil Water States in a Vertisol under Long-Term Direct Drill and Conventional Tillage
}

(1)

4

\author{
K. VAnderlinden ${ }^{\mathrm{a} *}$, Y.A. PAChePsky ${ }^{\mathrm{b}}$, A. Pedrera-PARrilla ${ }^{\mathrm{c}}$, G. MARTINeZ ${ }^{\mathrm{d}}$,
} A.J. ESPEJO-PÉREZ, F. PEREA ${ }^{\mathrm{c}}$, J.V. GIRÁLDEZ ${ }^{\mathrm{e}, \mathrm{f}}$

6

7 a IFAPA, Centro Alameda del Obispo, Avda. Menéndez Pidal s/n, 14004 Córdoba,

Spain.karl.vanderlinden@juntadeandalucia.es

${ }^{\mathrm{b}}$ EMFSL, USDA-ARS, Beltsville,MD,USA. yakov.pachepsky@ars.usda.gov

'IFAPA, Centro Las Torres-Tomejil, Ctra. Sevilla-Cazalla, km 12.2, Alcalá del Río

(Sevilla), Spain. aura.pedrera@juntadeandalucia.es;

francisco.perea.torres@juntadeandalucia.es

${ }^{\mathrm{d} D e p a r t a m e n t o ~ d e ~ F i ́ s i c a ~ A p l i c a d a, ~ U n i v e r s i d a d ~ d e ~ C o ́ r d o b a . ~ E d i f i c i o ~ d a ~ V i n c i . ~ C t r a . ~}$ Madrid km 396, 14071 Córdoba, Spain.z42magag@uco.es

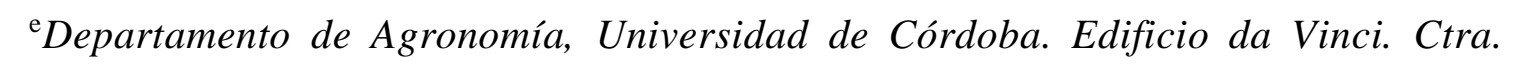
Madridkm 396,14071Córdoba,Spain.ajespejo@gmail.com;ag1gicej@uco.es

${ }_{\mathrm{f}}^{\mathrm{f}}$ Departamento de Agronomía, Instituto de Agricultura Sostenible, CSIC, Avda. Menéndez Pidal s/n, 14080 Córdoba, Spain.

This manuscript is intended for the Pedofract IX Special Issue 1

*Corresponding Author: Karl Vanderlinden (karl.vanderlinden@juntadeandalucia.es)

Running Title: Soil Water Retention and States under Direct Drill 
Understanding differences in the agro-hydrologic performance of Vertisols under conventional tillage (CT) and direct drill (DD) requires a thorough knowledge of the soil hydraulic properties. We measured water retention on 54 undisturbed topsoil $(0-0.05 \mathrm{~m})$ samples collected at the CT and DD plots from a long-term experiment. Water retention was significantly larger in DD $(p<0.05)$ for absolute pressure heads $(|h|)$ ranging from 63 to $3.2 \times 10^{3} \mathrm{~cm}$, and at $1.8 \times 10^{4}$ and $3.3 \times 10^{4} \mathrm{~cm}$. A comparison of the equivalent poresize distributions showed combined effects of tillage in the CT topsoil and compaction as a result of machinery traffic and natural consolidation in the DD topsoil, increasing and decreasing the amount of the largest pores in CT and DD, respectively, in favor of a larger abundance of smaller equivalent pore-sizes in DD than in CT. Significant differences in water retention and abundance of equivalent pore-sizes near the dry end of the soil water retention curve $\left(|h| \approx 4 \times 10^{4} \mathrm{~cm}\right)$ appear to be associated with the larger organic matter content in DD. These results were corroborated by field-measured soil water content data (0-0.10 and $0.25-0.35 \mathrm{~m})$, showing a persistently larger soil water content in DD than the spatial average of both tillage systems. Differences in the observed trimodal soil water content probability density functions between CT and DD were related to equivalent poresizes for which significantly different water retentions were measured. This work elucidates direct and indirect effects of soil management on water retention and the equivalent pore-size distribution, with important consequences for the soil's agrohydrologic performance.

Keywords: Conventional tillage, Direct drill, Pore-size distribution, Soil management, Soil water content, Soil water retention, Vertisol 


\section{Highlights}

54

- Water retention, pore-size distribution and field soil water states of a vertisol under conventional tillage and direct drill are compared

- Direct drill yields larger water retention for $63<|h|<3.2 \times 10^{3} \mathrm{~cm}$, and at $|h|=1.8$ $\times 10^{4}$ and $3.3 \times 10^{4} \mathrm{~cm}$.

- Larger water retention near $|h| \approx 4 \times 10^{4} \mathrm{~cm}$ in direct drill is associated with larger

60 organic matter content

- Field soil water states are controlled by specific SWRC and pore-size distribution ranges in both management systems

63

64 


\section{Introduction}

Understanding the hydrological functioning of rainfed soils under conservation soil management systems is key to explain their agronomic performance (Ordóñez et al., 2007; Pittelkow et al., 2015; Gristina et al., 2018; Foster et al., 2018 ) and potential for climate change adaptation and mitigation (Powlson et al., 2014; Ogle et al., 2019). This is particularly true in seasonally dry climates, where water-limiting conditions persist during long periods and soil water content becomes the single most important control for numerous ecohydrological and biogeochemical processes that take place at or near the soil surface (Wang et al., 2015). Under such environmental conditions and in the light of climate change, clay soils become of prime importance for dryland agriculture as a result of their capacity to retain large amounts of water and supply it to crops under conditions of large atmospheric water demand (Vanderlinden et al., 2017).

During the last decades, mainly motivated by environmental and economic concerns, the consequences of conservation tillage practices on these processes have been intensively studied (Soane et al., 2012; Pittelkow et al., 2015; Peña-Sancho et al., 2016). Tillage increases the amount of the largest pores while natural consolidation and compaction by machinery traffic destroy the largest pores and promote an increase in the number of smaller pores (Startsev and McNabb, 2001; Schwen et al., 2011; Pöhlitz et al., 2018). The interplay of both induces changes in the soil water retention curve (SWRC) and the hydraulic conductivity (Ahuja et al., 1998; Startsev and McNabb, 2001; Peña-Sancho et al., 2016). Only few studies on the effect of soil management on soil properties (Unger and Cassel, 1991; Ahuja et al., 2006) and their variability (Cassel and Nelson, 1985; Van Es et al., 1999) involved clays (Ordóñez et al., 2007; Strudley et al., 2008; Page et al., 
Recent developments based on the introduction of X-ray microtomography (e.g. Schlüter et al., 2018) in combination with emerging techniques for microscale mapping of microbiological activity (e.g. Kravchenko et al., 2019) or imaging of stabilized organic carbon sources within soil microaggregates (e.g. Arachchige et al., 2018) provide evidence that soil management (i.e. tillage, residue management and crop rotation) exerts effects on the abundance of specific pore-size intervals that are associated with greater enzymatic activities. These intervals are therefore deemed relevant for carbon turnover and storage, with possible effects on water retention at sub-micron pore-size scales. A specific knowledge gap exists regarding the interaction of soil management with the wellknown superior capacity of clay soils to supply water to crops under dry environmental conditions in comparison to other soil types (Pittelkow et al., 2015; Gristina et al., 2018; Page et al., 2019). commonly implemented on these soils by local farmers.

114 The objectives of this work were 1) to provide a detailed comparison of the measured and 
modelled SWRCs and the differential water capacity curves of a Vertisol under DD and CT with a wheat-sunflower-legume crop rotation, and 2) to relate the observed differences at specific pressure heads of the SWRC with observed field soil moisture states and patterns, and their spatio-temporal dynamics.

\section{Materials and methods}

\section{Study site}

The data used in this study were obtained in a long-term soil management experiment located at the Tomejil farm, Carmona (Seville), in SW Spain $\left(37^{\circ} 24^{\prime} \mathrm{N}, 5^{\circ} 35^{\prime} \mathrm{W}, 79\right.$ m.a.m.s.1.), where the agronomic and environmental effects of conventional tillage (CT), minimum tillage and direct drill (DD) are being compared since 1982 in a dryland wheat (Triticum durum L.) - sunflower (Helianthus annuus L.) - field pea (Pisum sativum L.) rotation. The treatments are quadruplicated in a completely randomized design within a 3.5-ha field, with elemental plot dimensions of $15 \times 180 \mathrm{~m}$. Data for this study were obtained in three pairs of adjacent CT and DD plots (Martinez et al., 2010). The same crop was grown on each elemental plot throughout the crop rotation. In the CT treatment, the $0.25-\mathrm{m}$ deep mouldboard plow pass and successive cultivator passes were implemented before sowing. In the DD treatment, no tillage whatsoever took place, except for a slight disturbance of the soil surface by a seed opener during sowing. Fertilizers were applied according to local agricultural practices and only when wheat was cultivated. About $220 \mathrm{~kg} \mathrm{ha}^{-1}$ of $18 \mathrm{~N}-46 \mathrm{P}_{2} \mathrm{O}_{5}-0 \mathrm{~K}_{2} \mathrm{O}$ was applied one week before sowing (November), and the second dose of $200 \mathrm{~kg} \mathrm{ha}^{-1}$ of urea was applied during the winter according to rainfall occurrence. Crop residues were left in the field in all treatments. 
According to the Köppen-Geiger classification (Peel et al., 2007), the study area climate is temperate Mediterranean with dry and hot summers (Csa) and Atlantic influence that dominates precipitation in the colder months. Rainfall is characterized by a large interand intra-annual variability and averages annually about $500 \mathrm{~mm}$, of which $58 \%$ and $35 \%$ occurs from October to January and from February to May, respectively. December is generally the wettest month $(91 \mathrm{~mm})$ while July and August are the driest months (1 and in August and average daily reference evapotranspiration (Penman-Monteith) ranges from 1.6 in December to $7.8 \mathrm{~mm}$ in July. Annual rainfall measured on-site with an automated rain gage (RIA, 2020) was 521 and $616 \mathrm{~mm}$ for 2008 and 2009, respectively.

According to the Soil Survey Staff (1999) and the IUSS Working Group WRB (2014), the soil is classified as a Chromic Haploxerert and a Haplic Vertisol, respectively. Clay content is uniform across the field (standard error $\sim 0.4 \%$ ) and increases slightly with depth from 55.5 to $60.0 \%$ at $0.6 \mathrm{~m}$ (Martinez et al., 2010). The composition of the clay fraction (40\% montmorillonite, $44 \%$ illite, $16 \%$ of kaolinite) explains the shrink-swell phenomena that characterize this soil, particularly the appearance of wide and deep cracks work under dry and wet conditions as a result of hard setting and stickiness, respectively.

Soil organic carbon (SOC) content in the field is rather small, on average $10 \mathrm{~g} \mathrm{~kg}^{-1}$ in the top $0.15 \mathrm{~m}$. Martínez et al. (2009) found significantly larger SOM in DD as compared to CT (11.6 and $9.2 \mathrm{~g} \mathrm{~kg}^{-1}$, respectively). Melero et al (2009) demonstrated the time and 
depth dependence of SOC, and its difference between DD and CT in this field. During the wheat growing season (March), they found significant differences only in the topsoil (0-0.3 m), with average SOC contents of 9.5 and $8.3 \mathrm{~g} \mathrm{~kg}^{-1}$ in DD and CT, respectively, and near $8.7 \mathrm{~g} \mathrm{~kg}^{-1}$ in both treatments in the subsoil $(0.3-0.5 \mathrm{~m})$. The topsoil SOC in DD and CT increased slightly after harvest (October) to 9.6 and $8.9 \mathrm{~g} \mathrm{~kg}^{-1}$, respectively, but the difference between both treatments was not significant. Subsoil SOC on the other hand, decreased after harvest to 8.0 and $7.5 \mathrm{~g} \mathrm{~kg}^{-1}$ in CT and DD, respectively, yielding a significant difference between both treatments.

\section{Water retention measurement and model}

Undisturbed surface soil samples were taken at 54 locations, evenly distributed over the three CT and DD plots on 6 Oct. 2006 using $0.05 \mathrm{~m}$ long and $0.04 \mathrm{~m}$ diameter stainless steel rings. The CT plots were last tilled on 15 March 2006, before sunflower was planted on 6 April 2006. Harvest took place in all plots on 10 August 2006. As a result, the time of sampling is representative for post-harvest soil conditions, in which both tillage treatments have undergone a full cycle of natural soil reconsolidation with extreme drying during the summer and rewetting after the first autumn rains.

Sand and sand-kaolin boxes (Eijkelkamp Agrisearch Equipment, The Netherlands) were used to measure water retention, $\theta_{\mathrm{r}}$, for $1 \leq|h| \leq 500 \mathrm{~cm}$, while a pressure plate apparatus (Soilmoisture Equipment Corp., USA) was used for $|h|=1000$ and $3000 \mathrm{~cm}$. A dew point psychrometer (WP4-TE, Decagon Devices, Inc., USA) was used to measure the dry end of the water retention curve, roughly for $3 \times 10^{3}<|h|<3 \times 10^{6} \mathrm{~cm}$. This yielded 27 SWRCs for each soil management system. The pressure head values were then grouped into 22 
classes, in each of which the average gravimetric water retention, $\Theta$, and standard deviation, $\sigma_{\Theta}$, were calculated. Eight classes corresponded to water retention measurements at eight pressure heads between 1 and $500 \mathrm{~cm}$, while for $|h|>500 \mathrm{~cm}$ class limits were established so that each class contained at least 27 water retention measurements. A t-test was performed for each class with the null hypothesis that the gravimetric water retention data in CT and DD come from populations with equal means The corresponding p-values are reported and interpreted as a probability of equal $\Theta$ in CT and DD.

The logarithmic differential water capacity (Soil Science Glossary Terms Committee, 2008), $C_{i}$, was calculated according to

$$
C_{i}=-\frac{\mathrm{d} \Theta_{i}}{\mathrm{~d}\left(\log _{10}|h|\right)},
$$

using the water retention measurements for each soil sample $i$. For each management system, individual $C_{i}$ values were grouped into 21 pressure head classes and the classaveraged logarithmic differential water capacity, $C$, and corresponding standard deviation, $\sigma_{C}$, were calculated. In addition, the probability of equal $C$ in CT and DD was computed for each class. The capillary hypothesis, based on the Young-Laplace equation, was used to calculate equivalent pore radii, $\delta$.

In order to obtain a continuous representation of the SWRC the sum of a double exponential (DE) model (Dexter et al., 2008) and the Groenevelt and Grant (GG) (2004) equation (Vanderlinden et al., 2017), 


$$
\Theta=A_{1} e^{\left(-|h| / h_{1}\right)}+A_{2} e^{\left(-|h| / h_{2}\right)}+k_{1}\left[e^{\left(-k_{0} / 6.9^{n}\right)}-e^{\left(-k_{0} /\left(\log _{10}|h|\right)^{n}\right)}\right]
$$

217 was fitted to the $\Theta$ data of both management systems. In the DE model, $h_{1}$ and $h_{2}$ are fitting parameters associated with characteristic pressure heads at which the structural and textural pore spaces empty, respectively, and parameters $A_{1}$ and $A_{2}$ are proportional to the volume of each of these pore spaces (Dexter et al., 2008). By adding the GG model in Eq. (2) only $h_{1}$ and $A_{l}$ maintain their physical meaning with respect to the structural pore space. The textural pore space is described by the last two terms of Eq. (2), where $k_{1}, k_{0}$ and $n$ are fitting parameters of the GG model. In accordance to Vanderlinden et al (2017), we distinguish hereinafter also between the inter- and intra-aggregate pore spaces of the clay microstructures, at scales ranging from a few nanometers to the micrometer.

The continuous representation of the logarithmic differential water capacity, $c$, was obtained for both management systems by differentiating Eq. (2) (Vanderlinden et al., 2017):

$$
c=\frac{\ln 10 A_{1}|h|}{h_{1}} e^{\left(-|h| / h_{1}\right)}+\frac{\ln 10 A_{2}|h|}{h_{2}} e^{\left(-|h| / h_{2}\right)}+k_{1} k_{0} n\left(\log _{10}|h|\right)^{-n-1} e^{\left(-k_{0} /\left(\log _{10}|h|\right)^{n}\right)},
$$

using the parameters obtained by fitting Eq. (2). Note that Eq. (3) is only valid for $|h|>0$. 
238 The gravimetric soil water content $(\theta)$ was surveyed in both management systems on 37 239 days between 23 Jan. 2008 and 21 July 2009 during a wheat-sunflower sequence. The 240 sampling period comprised 545 days with an average time interval between surveys of 15 days. On 2 Feb. 2010, 196 days after the last survey, an additional survey was conducted to capture the extremely wet soil conditions for the 2009-2010 winter when field pea was planted in the experimental field. Daily rainfall, temperature and reference crop evapotranspiration during the measurement period is provided in the Supplementary Material. Twenty-seven disturbed top- and subsoil samples were taken on each survey in each management system near $(<1.5 \mathrm{~m})$ the locations where the undisturbed samples were taken. A 0.05-m diameter Edelman hand auger was used to extract these samples from 00.10 and $0.25-0.35-\mathrm{m}$ depths. Samples were stored in airtight plastic bags and weighed and dried in the laboratory during $48 \mathrm{~h}$ at $105^{\circ} \mathrm{C}$.

Descriptive statistics were calculated for both management systems and both depths. A one-way ANOVA was performed to quantify the contribution of spatial (within survey variance) and temporal variability (between survey variance) to the total variance of the obtained soil water content datasets in both management systems.

In order to identify persistently wetter and dryer sampling locations in the field and associate these with the soil management, a temporal stability analysis was performed

$$
\varepsilon_{i j}=\frac{\theta_{i j}-\langle\theta\rangle_{j}}{\langle\theta\rangle_{j}}
$$


where the subscripts $i$ and $j$ represent location and time, respectively, and where

$\langle\theta\rangle_{j}$ is the spatial average of $\theta$ at time $j$. The mean relative difference, $M R D$, at location $i$ is

$$
M R D_{i}=\frac{1}{N_{t}} \sum_{j=1}^{j=N_{t}} \varepsilon_{i j}
$$

where $N_{t}$ is the number of observation times. The standard deviation of the relative differences over the observation period serves as a measure of the temporal stability and is computed as

$$
S D R D_{i}=\sqrt{\frac{1}{N_{t}-1} \sum_{j=1}^{j=N_{t}}\left(\delta_{i j}-M R D_{i}\right)^{2}}
$$

Hereinafter, the subscript $i$ is omitted in MRD and SDRD.

\section{Results}

\section{Soil water retention and differential water capacity}

Mean gravimetric water retention in both management systems showed overall a similar behavior but was significantly larger in DD $(p<0.05)$ for $|h|$ ranging from 63 to $3.2 \times 10^{3}$ $\mathrm{cm}$, with significant differences in $\Theta$ between CT and DD ranging from 0.006 to 0.015 $\mathrm{kg} \mathrm{kg}^{-1}$, and at $1.8 \times 10^{4}$ and $3.3 \times 10^{4} \mathrm{~cm}$, with significant differences in $\Theta$ of near 0.005 $\mathrm{kg} \mathrm{kg}^{-1}$ (Figs. 1a and 1b). The largest differences with the strongest significance were observed near $|h| \approx 600 \mathrm{~cm}\left(\Theta \approx 0.30 \mathrm{~kg} \mathrm{~kg}^{-1}\right)$. The standard deviation of $\Theta$ was larger in DD in the $10-10^{3} \mathrm{~cm}$ range, i.e. roughly the interval where $\Theta$ was significantly larger in DD. Standard deviations decreased for both management systems with increasing $|h|$, except near $|h|=6 \times 10^{3} \mathrm{~cm}$, where standard deviation peaked for both management systems, possibly as a result of the stronger uncertainty of the psychrometer 
measurements in this interval. Soil management did not affect water retention significantly at $|h|<31.6 \mathrm{~cm}$, nor did it show a significant effect near the air-entry pressure $(|h| \approx 10 \mathrm{~cm})$.

Significant differences in abundancies of equivalent pores with $\delta>1.5 \times 10^{5} \mathrm{~nm}(|h|<$ $10 \mathrm{~cm}$ ) were observed between DD and CT (Figs.1c and 1d). Conventional tillage showed a significantly larger abundance of pores $(p=0.046)$ near $\delta=9.4 \times 10^{5} \mathrm{~nm}$, while pores with $\delta=3.0 \times 10^{5} \mathrm{~nm}$ were significantly more abundant in DD $(p=0.036)$.

\section{Figure 1 near here}

For $10<|h|<200 \mathrm{~cm}$, the slope of the SWRC was steeper for CT than for DD, resulting in a larger abundance of equivalent pores in CT than in DD for the interval near $7.4 \times 10^{3}$ $<\delta<1.5 \times 10^{5} \mathrm{~nm}$ (Fig. 1). The difference in the abundance of pores between CT and DD $(p=0.065)$ reached a maximum near $\delta=8.4 \times 10^{4} \mathrm{~nm}(|h|=17 \mathrm{~cm})$ and decreased gradually as $\delta$ further decreased.

Near $\delta=4.7 \times 10^{3} \mathrm{~nm}(|h|=300 \mathrm{~cm})$ the abundance of equivalent pores became larger in $\mathrm{DD}(p=0.09)$, reaching a maximum difference $(p=0.07)$ with CT and a local minimum of the $C$ - $\delta$ curve near $\delta=2.1 \times 10^{3} \mathrm{~nm}(|h|=700 \mathrm{~cm})$, close to the limit between the structural and textural pore spaces (Fig. 1). This is also where the difference in $\Theta$ between CT and DD reaches maximum significance (Fig. 1b). The $C-\delta$ curves for CT and DD reach a second maximum near $\delta=200 \mathrm{~nm}\left(|\mathrm{~h}|=7.3 \times 10^{3} \mathrm{~cm}\right)$, corresponding to the second inflection point of the SWRC which represents the mode of the pore-size distribution of 
the textural pore space (Fig. 1c). Further, near $\delta=38 \mathrm{~nm}\left(|h|=3.9 \times 10^{4} \mathrm{~cm}\right.$ ), a local minimum is observed with a significantly $(p=0.01)$ larger portion of equivalent pores in DD, corresponding with the significantly larger $\Theta$ observed in DD at $|h|=1.8 \times 10^{4}$ and $3.3 \times 10^{4} \mathrm{~cm}$.

\section{Soil water retention and differential water capacity models}

Fig. 1a shows the fit of the SWRC model [Eq. (2)] to the measured $\Theta$ data and the corresponding fitting parameters for CT and DD. Despite the large coefficient of determination (0.99), the model fit near the air-entry pressure and for $10^{2}<|h|<10^{5}$ was not optimal, although the main features of the fitted SWRC models for CT and DD, as discussed in the preceding section, were preserved. The parameters $A_{1}$ and $h_{1}$ (Fig. 1a) were slightly smaller in DD as compared to CT, indicating that the structural pore space was smaller and emptied at a slightly smaller $|h|$ in DD than in CT (Dexter et al., 2008; Vanderlinden et al, 2017). Using Eq. (3) with the parameters shown in Fig. 1a to model the calculated $C$ - $\delta$ curves leads to an overestimation and underestimation of the modes of the structural and textural pore-size distributions, respectively, and an underestimation of the corresponding $\delta$ near the limit between the structural and textural pore spaces, for both CT and DD. This apparent discrepancy is partly due to the lack of fit of the SWRC models at specific pressure heads but is also a result of the coarse resolution of the calculated $C-\delta$ values.

\section{Field-measured gravimetric soil water content in DD and CT}

The topsoil $(0-0.10 \mathrm{~m})$ mean $\theta$ was $0.007 \mathrm{~kg} \mathrm{~kg}^{-1}$ larger in DD than in CT, with a probability of 0.13 that both means are statistically equal (Table 1 ). The mean subsoil $\theta$ (0.25-0.35 m) was $0.004 \mathrm{~kg} \mathrm{~kg}^{-1}$ larger than in the topsoil of both CT and DD, and was 
also $0.007 \mathrm{~kg} \mathrm{~kg}^{-1}$ larger in DD than in CT, with a probability of 0.06 that both means are statistically equal.

\section{Table 1 near here}

Table 2 shows that the largest proportion of the spatiotemporal variability in $\theta$ was a result of the variability between surveys, both in the top- and subsoil. For the topsoil, the variance between and within surveys was both larger in DD, while for the subsoil the between- and within-survey variances were larger in CT and DD, respectively. The ratio of the between- and within-survey variances was larger in CT for both soil depths but was substantially smaller for the subsoil.

\section{Table 2 near here}

\section{Temporal stability analysis of soil water content}

Soil water content in DD was on average wetter than the field-averaged water content. Most locations in CT were on average dryer than the field average at both depths (Figs. $2 \mathrm{a}$ and $2 \mathrm{~b}$ ). Nineteen and 21 out of the 27 sampling locations in DD indicated MRD $>0$, for the top- and subsoil, respectively. In CT, 23 and 19 out of 27 sampling locations showed MRD < 0 for the top- and subsoil, respectively. In the topsoil (Fig. 2a), the SDRD was generally larger in the wetter DD plots (MRD > 0) and smaller in the dryer CT plots, while no clear difference existed between CT and DD in the SDRD of the subsoil (Fig. $3 b)$.

\section{Figure 2 near here}


Spatiotemporal probability distribution of $\theta$ in DD and CT.

359 In both management systems, spatial probability density functions (pdfs) of $\theta$, measured on individual survey dates, followed generally normal distributions, except for the driest surveys when log-normal distributions were found as a result of accumulation of probability density towards the lower physical limit of $\theta$. For both management systems, the topsoil pdfs $(0-0.10 \mathrm{~m})$ showed a trimodal distribution, corresponding to three dominant soil moisture states (Fig 3a).

The probability that $\theta$ is smaller than the lower limit of the wet soil moisture state $(\theta \approx$ 0.21) was the same for CT and DD (Fig. 3a). For the intermediate and dry soil moisture states, the probability was slightly larger in CT than in DD and a larger frequency of the smallest $\theta$ could be observed in CT (Fig. 3a) for the dry state. The $\theta$ pdfs for the $0.25-$ 0.35-m layer (Fig. 3b) show that the dry state is practically absent at this depth for both management systems and that a larger probability of the smallest $\theta$ exists in CT as compared to DD in the intermediate soil moisture state.

Figure 3 near here

Discussion

Effect of tillage on soil water retention and differential water capacity

379 Soil management affected $\Theta$ only at specific pressure heads, corresponding roughly to the structural and inter-aggregate pore spaces (Fig.1) where $\Theta$ was significantly larger in 
the wet end of the SWRC, where smaller $\Theta$ is often related with reductions in the volume of the corresponding pore-space, as a result of soil compaction by machinery traffic (e.g. Startsev and McNabb, 2001; Schwen et al., 2011; Pöhlitz et al., 2018). This finding contrasts with the general belief that DD systems are more prone to soil compaction than CT systems (e.g. Moret and Arrúe, 2007), which would result in smaller $\Theta$ in DD at the wet end of the SWRC.

The small differences in $\Theta$ between CT and DD observed on the drier side of the SWRC appear to correspond to soil water contents near the permanent wilting point. This means that the soil in DD does not necessarily stores more water, but that the subsoil might be able to continue supplying water to crops when the soil under CT is already depleted and has shifted towards the dry state. This feature is extremely important for crop growth in water-limited environments with strong atmospheric water demand and allows extending the growing period several weeks, leading to the observed superior agronomic performance of the soil under DD in this field by Ordóñez et al. (2007).

The differential water capacity (Fig. 1c) provides a means to compare the proportion of specific equivalent pore-sizes in both management systems. Significant differences in the abundancies of equivalent pores were observed between DD and CT (Fig. 1c and 1d). Observed differences in the abundancies of the largest pores $\left(\delta>2.0 \times 10^{5} \mathrm{~nm}\right)$ between both management systems could be the result of a combined effect of tillage, increasing the number of the largest pores in CT, and compaction, which results in a loss of the largest pores in DD. Further, near the maximum of the pore-size distribution for the structural pore space (Fig1c), a smaller abundance of equivalent pores in DD was observed than in CT. This is possibly a result of compaction in DD, in agreement with 
the findings of Startsev and McNabb (2001) who noticed the strongest decrease of pores in the range $2.4 \times 10^{4}<\delta<2.9 \times 10^{4} \mathrm{~nm}(50<|h|<60 \mathrm{~cm})$ as a result of soil compaction due to skidder traffic. In contrast to DD, topsoil compaction by machinery traffic or natural reconsolidation is alleviated by soil tillage in $\mathrm{CT}$.

Ahuja et al. (1998) suggested that the effect of tillage is mostly limited to the wet end of the SWRC, affecting water retention up to pressure heads between 7 and 13 times the airentry pressure head. Startsev and McNabb (2001) found that after soil compaction due to skidder traffic $\Theta$ decreased for $|h|$ below the air-entry pressure, and increased slightly at larger pressure heads, decreasing the slope of the SWRC and flattening the corresponding peak of $C$ (mode of the pore-size distribution of the structural pore space), in a similar way as shown in Figs. 1a and 1c. Pore volumes of compacted soils were found to increase slightly between 200 and $300 \mathrm{~cm}$, while no appreciable effect of soil compaction could be observed for $|h|>500 \mathrm{~cm}$.

For this fine-textured soil we found that long-term CT, as compared to DD, significantly affected water retention in a broader $|h|$ range, encompassing both the structural and textural pore spaces (Figs 1a and 1b). The apparently limited effect of soil compaction on the abundance of the largest pores $\left(\delta>1.5 \times 10^{5} \mathrm{~nm}\right)$ could be a result of the expansive nature of this clay soil in combination with the Mediterranean climate, which guarantees intra-annual variations in water contents from near-saturation to complete dryness that induce complete contraction-expansion cycles. Such cycles may alleviate, at least in part, the negative effects of DD on compaction of the pore space composed of the largest pores (Chinn and Pillai, 2008). In addition, it is worthwhile recalling here that the CT samples were taken from tilled, but naturally consolidated soil (the CT plots were last tilled 7 
months before taking the samples). The greater abundance of equivalent pores in CT than in DD for $\delta>10^{4} \mathrm{~nm}$ can therefore be interpreted as a result of the interplay between tillage, natural consolidation, and compaction. The larger $\Theta$ in DD for $|h|<300 \mathrm{~cm}$ cannot be explained by tillage effects but could at least partly be caused by the gain in small pores at the expense of larger pores as a result of compaction in DD (Startsev and McNabb, 2001; Pöhlitz et al., 2018).

Water retention is known to depend also on organic matter content (Rawls et al., 2003; Ankenbauer \& Loheide, 2017; Bogie et al., 2018). The larger $\Theta$ in DD near $|h| \approx 300 \mathrm{~cm}$ can therefore also be attributed to the larger organic matter content observed in DD, particularly in the topsoil (Melero et al., 2011). Figure 1 shows that near the boundary between the capillary and the adsorptive intervals $\left(|h| \approx 10^{5} \mathrm{~cm}\right.$ ) of the SWRC (Or \& Tuller, 1999; Tuller \& Or, 2005), the textural pore space shows a minimum in the abundance of equivalent pores near $\delta=38 \mathrm{~nm}\left(|h|=3.9 \times 10^{4} \mathrm{~cm}\right)$, with a significantly larger portion of equivalent pores in DD. The organic substances retained in such small pores, associated with the water-filled porosity, are inaccessible for microorganisms due to pore-size exclusion (Killham et al., 1993). Although not yet fully understood, recent research elucidates the role of different pore-size ranges in the adsorption and stabilization processes of different forms of organic matter (Bailey et al., 2017; Arachchige et al., 2018; Kravchenko et al., 2019). Future advancements in this research venue will foreseeably shed light on the role of organic matter and its distribution across different pore-sizes in soil water retention.

\section{Persistence of gravimetric soil water content in DD}

Field-measured $\theta$ was similar in both soil management systems (Table 1) in accordance 
with the subtle differences observed between the SWRCs of CT and DD (Fig. 1). The differences in $\theta$ between CT and DD were of similar magnitude to those observed in $\Theta$.

It is noteworthy to recall that the mean $\theta$ values shown in Table 1 are spatiotemporal means. Consequently, the larger mean $\theta$ for DD is not necessarily only the result of a larger water storage capacity in DD for the wettest soil moisture state but is at least also in part a consequence of the stronger persistence of $\theta$ in DD, as also observed in Fig. 3.

While tillage exerts a homogenizing effect on $\theta$ in space and time (Table 2) in the topsoil, this effect appears to be limited below the tilled layer. In the subsoil, between-survey variance was larger in $\mathrm{CT}$ than in $\mathrm{DD}$, indicating of a stronger subsoil persistence of $\theta$ in DD than in CT. Also, the results of the temporal stability analysis (Figs. 2a and 2b) point towards persistently wetter soil conditions than the field average in DD. By maintaining $\theta$ above critical soil water thresholds for plant growth (e.g. wilting point, $|h|=1.5 \times 10^{4}$ $\mathrm{cm}$ ), DD enables an extension of the growing period, in contrast to CT, by delaying plant senescence and die-off under limited water supply, with the corresponding positive consequences for yield.

Relationship between the SWRC and the spatiotemporal probability distribution of $\theta$ in $D D$ and $C T$.

The temporal variability of $\theta$ was substantially larger than its spatial equivalent on specific survey dates, possibly as a result of the homogeneous nature of the clay soil of the study field (Table 2). Therefore, we consider pdfs of $\theta$ in time at different locations in space as realizations of the same underlying probability distribution of $\theta$ in time. The pdfs for DD and CT of $\theta$ in time can then be estimated by combining all the available $\theta$ measurements (27 locations in DD and CT, and 37 surveys) in spatiotemporal pdfs as 
The wet end of the topsoil pdfs corresponds to the wet dominant field soil moisture state which is related with the minimum in the $C-\delta$ curves and identified as the transition from the structural to the textural pore space (Fig. 1a). The greater abundance of the equivalent pore-sizes for $\mathrm{DD}$ as compared to $\mathrm{CT}$ at this minimum resulted in overall wetter conditions in DD in this soil moisture state, being $P\left(\theta \leq 0.28 \mathrm{~kg} \mathrm{~kg}^{-1}\right) 0.11$ larger for CT than for DD.

490

As a result of the large, but similar abundance of the equivalent pore-sizes for CT and DD near $|h|=7.2 \times 10^{3} \mathrm{~cm}$ and $\delta=200 \mathrm{~nm}$ (Fig.1c), similar probabilities of $\theta$ were observed in CT and DD near the lower limit of the wet soil moisture state (Fig. 3a). As a result of the large number of pores with these equivalent pore-sizes, fast transitions towards the drier intermediate field soil moisture state occur for small increments in $|h|$. This happens in a similar way in both management systems and results in a local minimum in the frequency near $\theta \approx 0.21$ (Fig 3a).

498

The dry end of the pdfs in Fig. 3a corresponds to the dry field soil moisture state in CT 500 and DD. The upper $\theta$ limit for this state corresponds roughly to the minimum in the $C-\delta$ curve, for which $\Theta$ and $C$ where significantly larger in DD (Fig. 1c). The significantly smaller abundance of equivalent pore-sizes in CT near this minimum might explain the larger probability of occurrence of the smallest $\theta$ in CT, the larger frequency of the smallest $\theta$ in CT (Fig. 3a). 
SWRCs and the logarithmic differential water capacity curves, are linked with specific field-scale soil water states. Subtle differences observed at the pore-scale between both soil management systems appear to explain contrasting soil water dynamics patterns observed at the field-scale.

The dry state of the topsoil plays a crucial role in conserving water in deeper layers. As a result, the dry state is practically not reached in the subsoil (Fig. 3b) in both management systems. Furthermore, in the intermediate soil moisture state, larger probabilities were obtained in CT for the smallest $\theta$. This feature is possibly at the core of the larger yields observed in DD during dry years (Ordóñez et al., 2007) or the superior performance of conservation agriculture in semi-arid regions (Pittelkow et al., 2015).

\section{Conclusions}

The water retention data obtained from a Vertisol under CT and DD, and the corresponding differential water capacity curves, provided relevant information for the detailed comparison of the equivalent pore-size distributions for both soil management systems. An earlier proposed model for the SWRC provided an overall good fit to the measured CT and DD data. The modelled differential water capacities reproduced the main features of the equivalent pore-size distributions satisfactorily.

Subtle differences in the magnitude of $\Theta$ and the shape of the SWRCs for CT and DD gave rise to differences in the equivalent pore-size distributions that explained differences in field-measured soil moisture pdfs, with persistently wetter topsoil conditions in DD in the dry and wet states. The significantly larger $\Theta$ and abundance 
of equivalent pores in DD towards the dry end of the SWRC, led to wetter field soil conditions in DD and might be linked to the larger organic matter content observed in DD.

Our results show that soil management has direct and indirect effects on the SWRC and the equivalent pore-size distribution and elucidate links between field-scale soil water states and the micro- and nanometer-scale pore-space organization, as affected by soil management. Further research is needed to achieve a full understanding of how soil management influences water retention at these scales.

\section{Acknowledgements}

Funding for this work came from the Spanish Ministry of Economy and Competitiveness and FEDER (Grant AGL2015-65036-C3-3-R), from the Junta de Andalucía (AGR-4782) and from IFAPA and FEDER (Grant AVA2019.018). Also support through PhD grant $\mathrm{n}^{\circ}$ 8 (Res. 15/04/2010) by IFAPA is acknowledged. Special thanks to E. Rodríguez, M. Morón, J. García, and M.A. Ayala of IFAPA Centro Las Torres-Tomejil for their assistance with the field and laboratory work. The authors have no conflict of interest to declare.

Data Availability Statement: The dataset used in this manuscript is available from the authors upon request.

Author Contributions: Study concept and design: K. Vanderlinden, J.V. Giráldez and F. Perea. Maintenance of experimental fields and data acquisition: F. Perea, A.J. Espejo-Pérez, A. Pedrera-Parrilla. Data analysis and interpretation of results: 
K.Vanderlinden, G. Martinez, Y.A. Pachepsky, J.V. Giráldez. Manuscript drafting: K.

558

559

560

561

562

563

564

565

566

567

568

569

570

571

572

573

574

575

576

577

578

579

580

581

Vanderlinden. All authors revised the draft and contributed significantly to the final version. Obtained funding: K. Vanderlinden and J.V. Giráldez

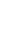

2

363

64

5

666

\section{References}

Ahuja, L.R., Fiedler, F., Dunn, G.H., Benjamin, J.G. \& Garrison, A. 1998. Changes in soil water retention curves due to tillage and natural reconsolidation. Soil Science Society of America Journal, 62, 1228-1233.

Ahuja, L.R., Ma, L. \& Timlin, D.J. 2006. Trans-disciplinary soil physics research critical to synthesis and modeling of agricultural systems. Soil Science Society of America Journal, 70, 311-326.

Ankenbauer, K.J. \& Loheide, S.P. 2017. The effects of soil organic matter on soil water retention and plant water use in a meadow of the Sierra Nevada, CA. Hydrological Processes, 31, 891-901.

Arachchige, P.S.P., Hettiarachchi, G.M., Rice, C.W., Dynes, J.J., Maurmann, L., Wang, J., Karunakaran, C., Kilcoyne A.L.D., Attanayake, C.P., Amado, T.J.C. \& Fiorin, J.E. 2018. Sub-micron level investigation reveals the inaccessibility of stabilized carbon in soil microaggregates. Scientific Reports, 8, 16810.

Bailey, V.L., Smith, A.P., Tfaily, M., Fansler, S.J. \& Bond-Lamberty, B. 2017. 
Differences in soluble organic carbon chemistry in pore waters sampled from different pore size domains. Soil Biology and Biochemistry, 107, 133-143.

Bogie, N.A., Bayala, R., Diedhiou, I., Dick, R.P. \& Ghezzehei, T.A. 2018. Alteration of soil physical properties and processes after ten years of intercropping with native shrubs in the Sahel. Soil \& Tillage Research, 182, 153-163.

Cassel, D.K. \& Nelson, L.A. 1985. Spatial and temporal variability of soil physical properties of Norfolk loamy sand as affected by tillage. Soil \& Tillage Research, 5, 517.

Chinn, C. \& Pillai, U.P.P. 2008. Self-repair of compacted Vertisols from central Queensland, Australia. Geoderma, 144, 491-501.

Dexter, A.R., Czyż, E.A., Richard, G. \& Reszkowska, A. 2008. A user-friendly water retention function that takes account of the textural and structural pore spaces in soil. Geoderma, 143, 243-253.

Foster, J.L., Bean, M.E., Morgan, C., Morgan, G., Mohtar, R., Landivar, J. \& Young, M. 2018. Comparison of two tillage practices in a semi-arid cotton-grain sorghum rotation. Agronomy Journal, 110, 1572-1579.

Gristina, L., Keesstra, S. \& Novara, A. 2018. No-till durum wheat yield success probability in semi arid climate: A methodological framework. Soil \& Tillage Research, 181, 29-36.

Groenevelt, P.A., \& Grant, C.D. 2004. A new model for the soil-water retention curve that solves the problem of residual water contents. European Journal of Soil Science, 55, 479-485.

IUSS Working Group WRB. 2014. World Reference Base for Soil Resources 2014. International soil classification system for naming soils and creating legends for soil maps. World Soil Resources Reports No. 106. FAO, Rome. 
Jensen, J.L., Schjønning, P., Watts, C.W., Christensen, B.T. \& Munkholm, L.J. 2019. Soil Water Retention: Uni-modal models of pore-size distribution neglect impacts of soil management. Soil Science Society of America Journal, 83, 18-26.

Killham, K., Amato, M. \& Ladd, J.N. 1993. Effect of substrate location in soil and soil pore-water regime on carbon turnover. Soil Biology and Biochemistry, 25, 57-62.

Kravchenko, A.N., Guber, A.K., Razavi, B.S., Koestel, J., Quigley, M.Y., Robertson, G.P. \& Kuzyakov, Y. 2019. Microbial spatial footprint as a driver of soil carbon stabilization. Nature Communications, 10, 3121.

Martínez, G., Vanderlinden, K., Giráldez, J.V., Espejo, A.J. \& Muriel, J.L. 2010. Fieldscale soil moisture pattern mapping using electromagnetic induction. Vadose Zone Journal, 9, 871-881.

Martinez, G., Vanderlinden, K., Ordóñez, R. \& Muriel, J.L. 2009. Can apparent electrical conductivity improve the spatial characterization of soil organic carbon? Vadose Zone Journal, 8, 586-593.

Melero, S., López-Garrido, R., Madejón, E., Murillo, J.M., Vanderlinden, K., Ordóñez, R. \& Moreno, F. 2009. Long-term effects of conservation tillage on organic fractions in two soils in southwest Spain. Agriculture, Ecosystems \& Environment, 133, 68-74.

Melero, S., Pérez-de-Mora, A., Murillo, J.M., Buegger, F., Kleinedam, K., Kublik, S., Vanderlinden, K., Moreno, F. \& Schloter, M. 2011. Denitrification in a vertisol under long-term tillage and no-tillage management in dryland agricultural systems: Key genes and potential rates. Applied Soil Ecology, 47, 221-225.

Moret, D. \& Arrúe, J.L. 2007. Dynamics of soil hydraulic properties during fallow as affected by tillage. Soil \& Tillage Research, 96, 103-113.

Ogle, S.M., Alsaker, C., Baldock, J., Bernoux, M., Breidt, F.J., McConkey, B., Regina, K. \& Vazquez-Amabile, G.G. 2019. Climate and soil characteristics determine where 
no-till management can store carbon in soils and mitigate greenhouse gas emissions. Scientific Reports, 9, 11665.

634

Or, D. \& Tuller, M. 1999. Liquid retention and interfacial area in variably saturated porous media: Upscaling from single-pore to sample-scale model. Water Resources Research, 35, 3519-3606.

Ordóñez, R., González, P., Giráldez, J.V. \& Perea, F. 2007. Soil properties and crop yields after 21 years of direct drilling trials in southern Spain. Soil \& Tillage Research, 94, 4754.

Page, K.L., Dang, Y.P., Dalal, R.C., Reeves, S., Thomas, G., Wang, W. \& Thompson, J.P. 2019. Changes in soil water storage with no-tillage and crop residue retention on a Vertisol: Impact on productivity and profitability over a 50 year period. Soil \& Tillage Research, 194, 104319.

Peel, M.C., Finlayson, B.L. \& McMahon, T.A. 2007. Updated world map of the KöppenGeiger climate classification. Hydrological Earth Systems Sciences, 11, 1633-1644.

Peña-Sancho, C., López, M.V., Gracia, R. \& Moret-Fernández, D. 2016. Effects of tillage on the soil water retention curve during a fallow period of a semiarid dryland. Soil Research, 55, 114-123.

649

Perea, F. \& González, P. 2005. Origen, clasificación y caracterización de los suelos de la Campiña de Carmona. CAREL, 3, 16 p. http://www.carmona.org/publicaciones/carel/2004_2.pdf.

Pittelkow, C.M., Liang, X., Linquist, B.A., Van Groenigen, K.J., Lee, J., Lundy, M.E., van Gestel, N., Six, J., Venterea, R.T. \& van Kessel, C. 2015. Productivity limits and potentials of the principles of conservation agriculture. Nature, 517, 365-368. 

tillage, mulch tillage and no tillage. Soil \& Tillage Research, 175, 205-216.

658

659

660

661

662

663

664

665

666

667

668

669

670

671

672

673

674

675

676

677

678

679

680

681

Powlson, D.S., Stirling, C.M., Jat, M.L., Gerard, B.G., Palm, C.A., Sanchez, P.A. \& Cassman, K.G. 2014. Limited potential of no-till agriculture for climate change mitigation. Nature Climate Change, 4, 678-683.

Rawls, W.J., Pachepsky, Ya.A., Ritchie, J.C., Sobecki, T.M. \& Bloodworth, H. 2003. Effect of soil organic carbon on soil water retention. Geoderma, 116, 61-76.

RIA, 2020. Red de información agroclimática. IFAPA, Junta de Andalucía.

Schlüter, S., Großmann, C., Diel, J., Wu, G.M., Tischer, S., Deubel, A., \& Rücknagel, J. 2018. Long-term effects of conventional and reduced tillage on soil structure, soil ecological and soil hydraulic properties. Geoderma, 332, 10-19.

Schwen, A., Hernandez-Ramirez, G., Lawrence-Smith, E.J., Sinton, S.M., Carrick, S., Clothier, B.E., Buchan, G.D., Loiskandl, W. 2011. Hydraulic properties and the waterconducting porosity as affected by subsurface compaction using tension infiltrometers. Soil Science Society of America Journal, 75, 822-831.

Soane, B.D., Ball, B.C., Arvidsson, J., Basch, G., Moreno, F. \& Roger-Estrade, J. 2012. No-till in northern, western and south-western Europe: a review of problems and opportunities for crop production and the environment. Soil \& Tillage Research, 118, 66-87.

Soil Science Glossary Terms Committee. 2008. Glossary of soil science terms. SSSA, Madison, WI.

Soil Survey Staff. 1999. Soil Taxonomy: A basic system of soil classification for making and interpreting soil surveys. $2^{\text {nd }}$ ed. Agric. Hbk. 436. U.S. Gov. Print. Office, Washington, DC.

Startsev, A.D. \& McNabb, D.H. 2001. Skidder traffic effects on water retention, poresize distribution, and van Genuchten parameters of boreal forest soils. Soil Science 
683 Strudley, M.W., Green, T.R. \& Ascough II, J.C. 2008. Tillage effects on soil hydraulic 684 properties in space and time: State of the science. Soil \& Tillage Research, 99, 4-48.

Tuller, M., \& Or, D. 2005. Water films and scaling of soil characteristic curves at low $686 \quad$ water contents. Water Resources Research, 41, W09403.

687 Unger, P.W. \& Cassel, D.K. 1991. Tillage implement disturbance effects on soil 688 properties related to soil and water conservation: a literature review. Soil \& Tillage 689 Research, 19, 363-382.

690 Vanderlinden, K, Pachepsky, Y.A., Pederera-Parrilla, A., Martínez, G., Espejo-Pérez, 691 A.J., Perea, F. \& Giráldez, J.V. 2017. Water Retention and Preferential States of Soil 692 Moisture in a Cultivated Vertisol. Soil Science Society of America Journal, 81, 1-9.

693 Vanderlinden, K., Vereecken, H., Hardelauf, H., Herbst, M., Martínez, G., Cosh, M.H. \& 694 Pachepsky, Y.A. 2012. Temporal stability of soil water contents: A review of data and 695 analyses. Vadose Zone Journal, 11, doi:10.2136/vzj2011.0178.

696 Van Es, H.M., Ogden, C.B., Hill, R.L., Schindelbeck, R.R. \& Tsegaye, T. 1999. 697 Integrated assessment of space, time, and management-related variability of soil 698 hydraulic properties. Soil Science Society of America Journal, 63, 1599-1608.

699 Wang, L., Manzoni, S., Ravi, S., Riveros-Iregui, D. \& Caylor, K. 2015. Dynamic 700 interactions of ecohydrological and biogeochemical processes in water-limited systems. $701 \quad$ Ecosphere, 6,133 
Table 1. Descriptive statistics of field-measured gravimetric soil water content, $\theta$ ( $\mathrm{kg} \mathrm{kg}^{-}$ ${ }^{1}$ ) in conventional tillage (CT) and direct drill (DD), and probability that mean $\theta$ is the same in CT and DD.

\begin{tabular}{lcccccccc}
\hline$\theta$ & $\mathrm{m}$ & $\min$ & $\max$ & $\sigma$ & $\mathrm{CV}$ & skew. & kurt. & $p$ \\
\hline CT & 0.214 & 0.050 & 0.324 & 0.065 & 0.306 & -0.796 & -0.060 & 0.129 \\
DD & 0.221 & 0.048 & 0.356 & 0.067 & 0.302 & -0.795 & -0.044 & \\
& & & & $0.25-0.35 \mathrm{~m}$ & & & \\
CT & 0.218 & 0.095 & 0.341 & 0.052 & 0.238 & -0.040 & -0.904 & 0.057 \\
DD & 0.225 & 0.071 & 0.320 & 0.048 & 0.212 & -0.227 & -0.825 & \\
\hline
\end{tabular}


745 Table 2. Comparison of the temporal and spatial variability of field-measured soil water content, $\theta\left(\mathrm{kg} \mathrm{kg}^{-1}\right)$, in conventional tillage (CT) and direct drill (DD). The variance between and within surveys, and the $F$ ratio as calculated for one-way ANOVA.

\begin{tabular}{lccc}
\hline & $\begin{array}{c}\text { Variance between } \\
\text { surveys }\end{array}$ & Variance within surveys & $F$ \\
\hline & & $0-0.10 \mathrm{~m}$ & \\
CT & 0.162 & $3.80 \times 10^{-4}$ & 426 \\
DD & 0.172 & $4.58 \times 10^{-4}$ & 375 \\
& & $0.25-0.35 \mathrm{~m}$ & \\
CT & $8.65 \times 10^{-2}$ & $3.36 \times 10^{-4}$ & 257 \\
DD & $7.51 \times 10^{-2}$ & $3.67 \times 10^{-4}$ & 204 \\
\hline
\end{tabular}

748

749

750

751

752

753

754

755

756

757

758

759

760

761

762

763

764

765

766

767 
Fig. 1. a) Mean gravimetric water retention, $\Theta$, fit according to Eq. (2) and standard deviation of gravimetric water retention, $\sigma_{\Theta}$, for conventional tillage (CT) and direct drill (DD), plotted as a function of the logarithm of pressure head, $|h|$. The arrow indicates the approximate value of the air-entry pressure; b) probability that $\Theta$ is the same in both management systems, as a function of $|h|$; c) Mean logarithmic differential water capacity, $C$, model [Eq. (3)] using parameters shown in a) and standard deviation of the logarithmic differential water capacity, $\sigma_{C}$, for CT and DD, plotted as a function of the logarithm of equivalent pore radius, $\delta$; and d) probability that $C$ is the same in both management systems, as a function of $\delta$. Vertical dashed lines indicate characteristic points of the SWRC.

Fig.2. Relationship between the mean relative differences of soil water content (MRD) and the corresponding standard deviations (SDRD) for a) topsoil $(0-0.10 \mathrm{~m})$, and $\mathrm{b}$ ) subsoil $(0.25-0.35 \mathrm{~m})$. The vertical dashed line represents $\mathrm{MRD}=0$. Points close to this line represent locations with soil water contents close to the field-average soil water contents.

Fig 3. Spatiotemporal probability distributions of field-measured gravimetric soil water content, $\theta$, at depth intervals of (a) 0-0.10 m, and (b) 0.25-0.35 m for conventional tillage (CT) and direct drill (DD). The vertical dashed lines indicate the upper limit of the dry soil moisture state and the lower limit of the wet state.

\section{Table captions}

795

796
Table 1. Descriptive statistics of field-measured gravimetric soil water content, $\theta$ ( $\mathrm{kg} \mathrm{kg}^{-}$ ${ }^{1}$ ) in conventional tillage (CT) and direct drill (DD), and probability that mean $\theta$ is the same in CT and DD.

Table 2. Comparison of the temporal and spatial variability of field-measured soil water content, $\theta\left(\mathrm{kg} \mathrm{kg}^{-1}\right)$, in conventional tillage (CT) and direct drill (DD). The variance between and within surveys, and the $F$ ratio as calculated for one-way ANOVA. 
$807 \quad$ Figures

808 

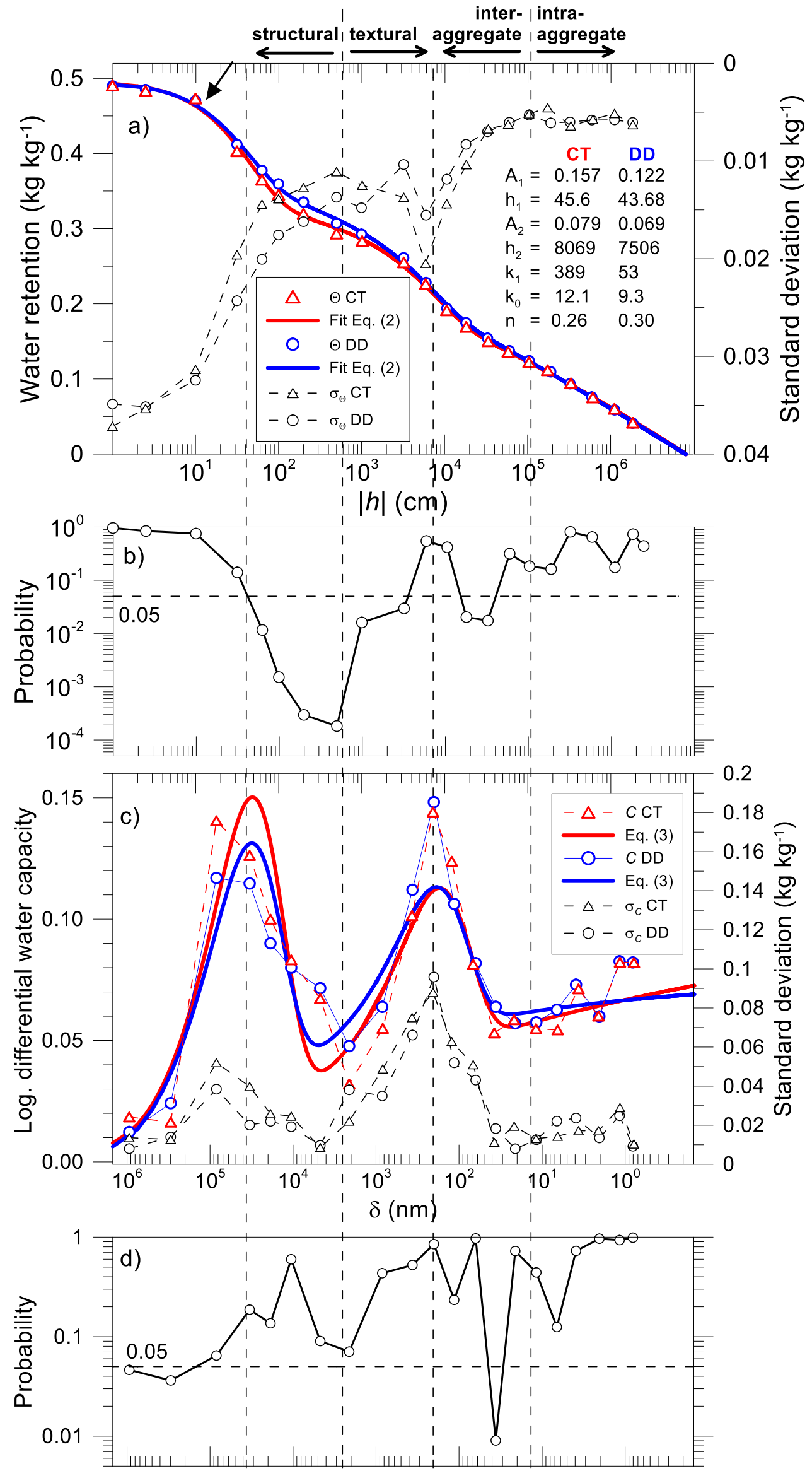

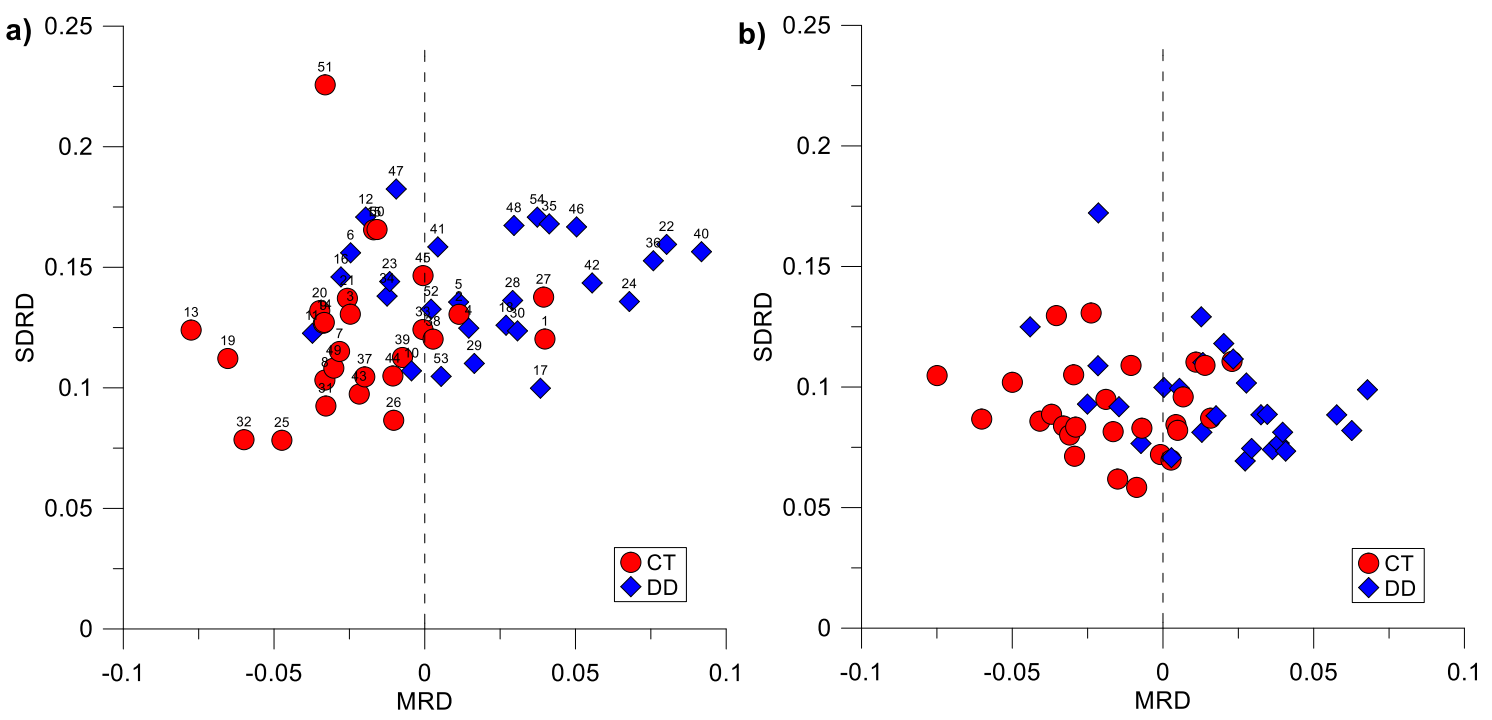

816

Figure 2

817

818 


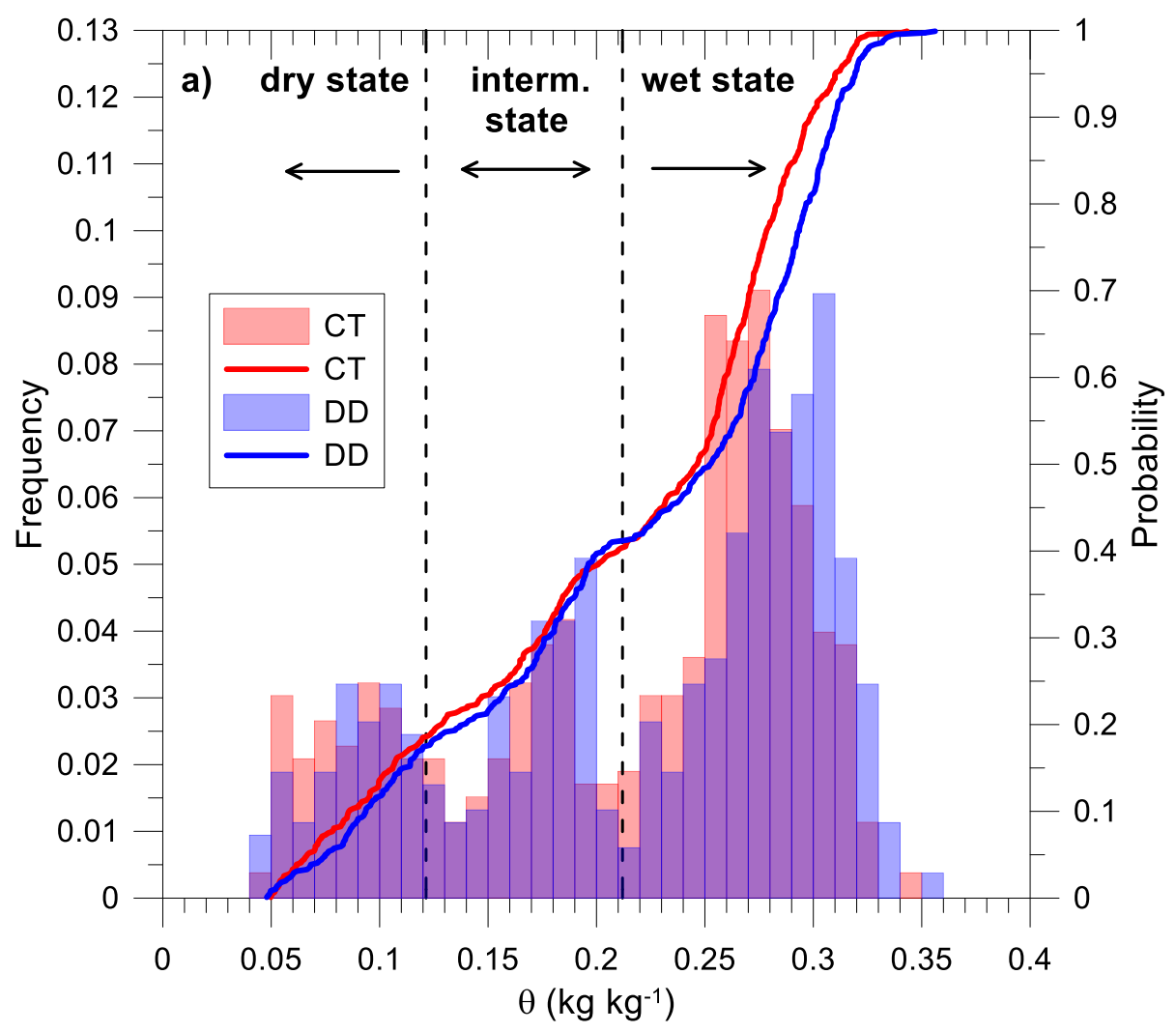

820

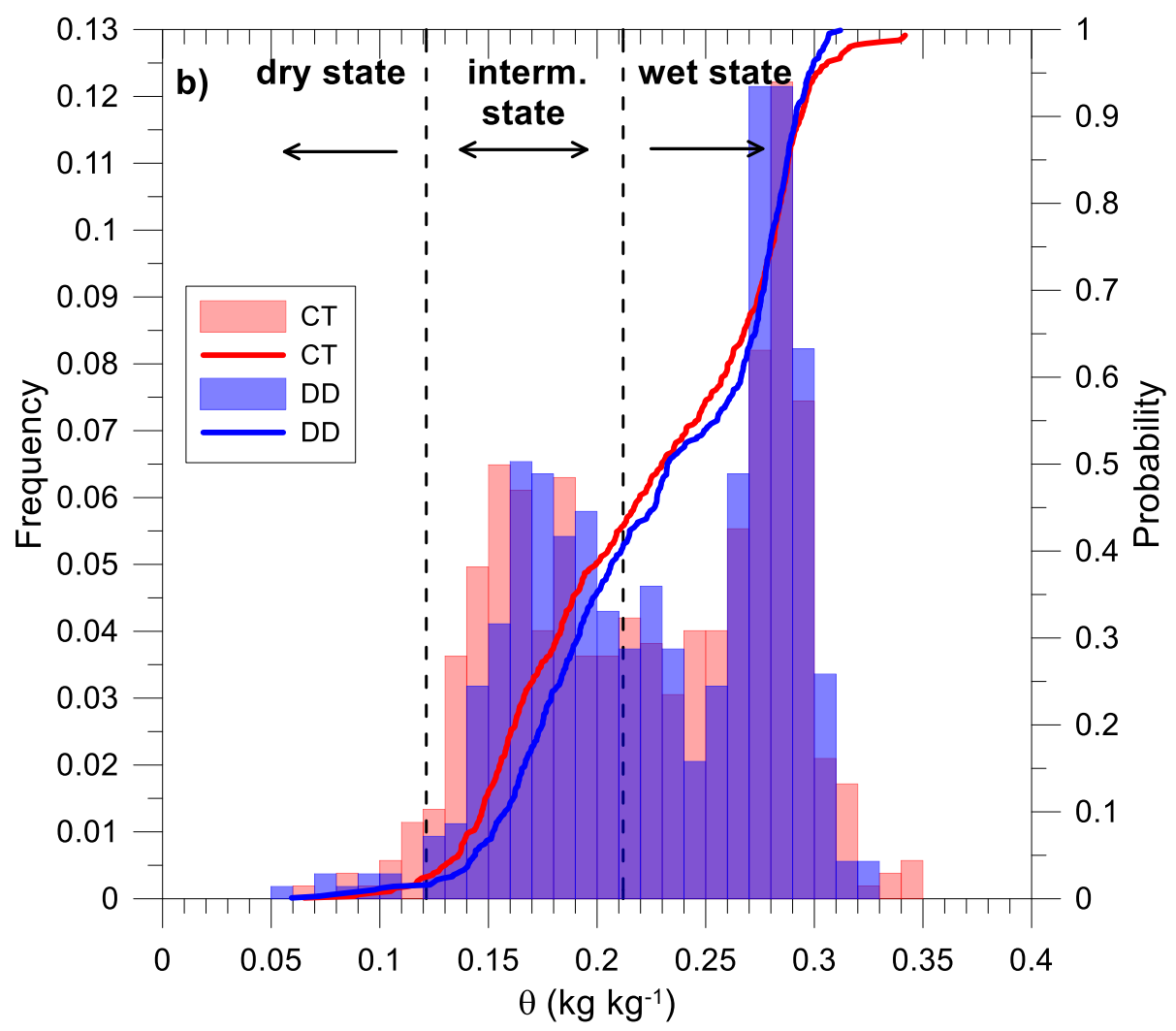

